\title{
On The Belt and Road Initiative and Chinese-Foreign Cooperative Program
}

\author{
Haiying $\mathrm{Ma}^{1, \mathrm{a}^{*}}$, Rangjia Cai ${ }^{2, \mathrm{~b}}$ and Yongteng $\mathrm{Ma}^{3, \mathrm{c}}$ \\ ${ }^{1,2,3}$ School of Economics, Northwest Minzu University, Lanzhou (730124), P.R.China

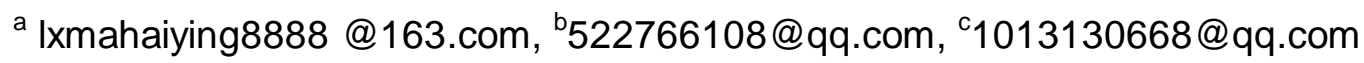

Keywords: The Belt and Road Initiative; higher education; Chinese-foreign cooperative education; current situation; Chinese universities

\begin{abstract}
Chinese-foreign cooperative program is an important part of The Belt and Road Initiative. The proposal of The Belt and Road initiative put forward new development requirements for China's education. As an important part of China's educational undertakings and an important way to educate international cooperation and exchange, Chinese-foreign cooperative education has become the focus of attention in the new period. The article systematically summarized the development status of China's Chinese-foreign cooperative education in the areas of regional distribution, program level, program mode, and disciplines in countries and regions along The Belt and Road initiative. It explored the problems faced by participating in cooperative education along the route, and at the same time further improved The Belt and Road initiative for Chinese-foreign cooperative education has made recommendations.
\end{abstract}

\section{Introduction}

Chinese-foreign cooperation in running schools is an important manifestation of the level of internationalization of higher education and the degree of opening up to the outside world. With the advancement of the Belt and Road Initiative, Chinese-foreign cooperative education will usher in a new historic development opportunity. As of March 2016, the number of Chinese-foreign cooperative education projects (institutions) that have been approved for establishment or organization in China has reached 2,403. The level of education involves all levels except compulsory education and military, police, politics, and religion. In 2015, the National Vision and Action for Promoting the Co-construction of the Silk Road Economic Belt and the 21st Century Maritime Silk Road, talent exchange and education cooperation have become important topics. The document mentioned "China wants to expand the scale of international students with countries along the route and cooperate in running schools.

In this regard, the academic community generally believes that The Belt and Road initiative is an upgraded version of the country's open development strategy for the outside world, and that China's foreign exchange and cooperation will enter a stage of upgrading and upgrading; While strengthening the Chinese-foreign cooperation in running schools, The Belt and Road can not only enhance the diplomatic relations between countries and promote the progress and improvement of economy, culture, and science and technology, but also, to a large extent, enhance the country's overall international position and increase the number of countries. Discourse power and comprehensive influence. In addition, some studies also believe that through the "Belt and Road" countries to promote the reform of the supply side of the talent structure, there will be more foreign educational institutions with rich experience in running schools, running schools, and the strength to run schools to invest in schools in China to increase student competition.

\section{Status of Chinese-foreign Cooperation in Running Schools along the Belt and Road Initiative}

The Belt and One Road construction is open and inclusive. Since The Belt and Road initiative was put forward, it has received positive responses from many countries and international organizations along the route. In this paper, 64 countries such as Mongolia, Kazakhstan, and Uzbekistan, which are currently generally recognized, are selected as research objects. The relevant data of Chinese-foreign 
cooperation in running schools mainly comes from educational information announced by the Ministry of Education's Education and Foreign-related Supervision Information Network, including institutions and projects approved by the Ministry of Education (undergraduate and higher levels) and institutions and projects filed by the Ministry of Education for the approval of the Ministry of Education.

Regional Distribution. As of March 2016, educational institutions in eight countries including Singapore, Malaysia, Thailand, India, Belarus, Ukraine, Russia, Poland and other countries participated in China-foreign cooperation along The Belt and Road. There are 190 cooperative construction projects (institutions), including 183 projects and 7 institutions. Russia's educational institutions have the largest number of projects (institutions) involved in construction, accounting for $66 \%$ of the total number of construction projects participating along the route, and $57 \%$ of the total number of institutions.

The Foreign Partner. a total of 89 educational institutions, including along the National University of Singapore and Nanyang Technological University, etc., involved in the construction of Chinese-foreign cooperative education project (institution) of. According to the comprehensive ranking of the world universities released by the educational organization Quacquarelli Symonds (QS) in 2016, 9 of the 89 educational institutions are famous in the QS, accounting for $10 \%$. Eight countries participating in the project (institutional) construction have a total of 70 colleges and universities listed on the QS, and about $13 \%$ of them participate in the construction of Chinese-foreign cooperative education projects (institutions).

Program Level. School-running projects (institutions) participating in construction along the line involves three levels: college, undergraduate and master degree. Among them, the project is dominated by the undergraduate level, accounting for $66 \%$; the proportion of the master's level project is the least, accounting for $3.8 \%$. Institutions are mainly at the specialist level, accounting for $71 \%$ of the total.

Program Mode. The modes of running schools (institutions) at all levels participating in construction along the line are various. Specialist-level projects (institutions) are all included in our national enrollment plan. Among them, there are 11 projects (institutions) issued by the Chinese side only accounting for 18\%; 49 projects (institutions) are jointly issued by both Chinese and foreign diplomas or academic certificates, accounting for $82 \%$. All undergraduate projects (institutions) participating along the route are included in the national enrollment plan. Among them, 18 projects (institutions) jointly issued degree certificates by Chinese and foreign parties, accounting for 15\%; 105 projects (institutions) only granted by the Chinese, accounting for $85 \%$. Among the graduate-level projects (institutions), 6 projects (institutions) are recruited on their own, and all are enrolled by foreigners, accounting for $75 \%$ of the total; and 2 projects (institutions) are included in the national enrollment plan of China.

\section{Subjects and Professions.}

Undergraduate and Higher Level Projects (institutions). The projects (institutions) that participate in construction along the line involve a variety of subject areas. According to the professional division of The Undergraduate Professional Catalogue (2012) of the Ministry of Education, undergraduate and higher level projects (institutions) participating in construction along with 10 disciplines and 62 professional orientations. The most involved in the construction of science is engineering, accounting for $27.4 \%$ of the total number of projects (institutions); followed by arts and management, accounting for $18.5 \%$ and $16.3 \%$, respectively; the least organized is history, only one project. Compared with the 12 disciplines listed in the "Undergraduate Professional Catalogue (2012) of the General Higher Education Institutions, the undergraduate and higher level projects (institutions) participating along the line have not been involved in two subject areas such as philosophy and agronomy.

College Level Education (institutions). According to the professional division of the Ministry of Education's Higher Professional Education (Specialized Professional Catalogue) (2015), the specialist-level projects (institutions) that participate in construction along the line involve 40 professional orientations, belonging to 12 professional categories and 26 Professional categories. Among them, the largest number of projects (institutions) was held in the financial and trade category, accounting for $34.2 \%$, and there were only a few major projects (institutions) for energy power and materials, biology, chemical engineering, and water conservancy. Compared with the 19 major 
categories listed in the Higher Professional Education (Specialty) Professional Catalogue (2015) of the General Higher Education Institutions, the specialized college-level educational projects (institutions) participating along the line have not yet addressed agriculture, forestry, animal husbandry and fisheries, resources, environment, and security. There are 7 professional fields such as light industry textile, food and medicine, food, medical and health, public security and justice, public management and service. See Table 6 for the distribution of professional majors of the sub-projects (institutions) under the line.

\section{Main Issues by Cooperation Program along the Belt and Road Countries}

The Small Overall Scale and the Unbalanced Regional Distribution. Judging from the total amount of existing projects (institutions), the number of Chinese-foreign cooperatively-run schools (institutions) participating along the route only accounts for less than $1 / 10$ of the total number of approved projects (institutions) in the country. From the perspective of the regional distribution of foreign partners participating in running schools, only 8 countries along the route participated in the project (institutional) construction, accounting for $1 / 8$ of the total number of countries and regions along the route. Moreover, nearly $70 \%$ of the projects (institutions) have foreign cooperation agencies from Russia, and Mongolia, Central Asia and West Asia and North Africa have not yet had educational institutions participate in the construction of Chinese-foreign cooperative education projects (institutions). The scale of cooperation in running schools along the line and the regional distribution are still far from meeting the needs of the Belt and Road Initiative.

Inadequate Introduction of Quality Education Resources. The introduction of quality educational resources is the purpose of Chinese-foreign cooperative education. The choice of partners and cooperation models is the key to determining whether effective introduction of quality educational resources is possible. For universities in China, cooperation with well-known foreign institutions of higher education and the development of a double certificate cooperation model can guarantee the introduction of quality education resources to the maximum. Nearly 90 educational institutions along the route participate in the construction of Chinese-foreign cooperative education projects (institutions). However, only one percent of universities and colleges are listed on the QS, among which the top 200 universities in the world are only two (National University of Singapore, Nanyang Technological University). The overall educational level of educational institutions participating in cooperative education along the line is not high. At the same time, the percentage of undergraduate programs (institutions) participating in the project along the line to issue double certificates is only $15 \% .75 \%$ of master's level programs (institutions) carry out independent enrollment, and diplomas are issued by foreign counterparts. In general, the ability to introduce high-quality education resources along the line needs to be improved.

Unreasonable Hierarchy. The development of Chinese-foreign cooperative education to a high level should be a step-by-step approach to high-level development and form a rational structure that covers all levels of higher education. At present, the level of project participation in the project along the line is mainly undergraduates and specialist whiles the undergraduate level or above only accounts for less than $4 \%$ of the total, and the doctoral level project is blank. There are $70 \%$ of specialists in the institution, and only 1 undergraduate and master's level are established. The overall level of education is low.

Uneven Distribution of Disciplines and Convergence of Professional Settings. The undergraduate and higher level programs that participate along the route are concentrated in engineering, arts, and management disciplines. The computer science and technology majors account for a quarter of the number of engineering disciplines. At the specialist level, professional majors such as financial and business commerce account for a considerable proportion. In the educational projects (institutions) at all levels, China's current urgently needed energy, resources, environment, agriculture, and bio-chemical industries are too few or even blank. At the same time, the phenomenon of "chain store" education still exists. For example, the Russian National University of the Pacific, Vladivostok State Medical University, Vladivostok National University of Economic Services, St. Petersburg State University of Marine Technology, etc. cooperated with two different universities in China for the same specialty, 
while the Russian cloth The National Engineering University of Lagoveschensk actually cooperated with 4 universities in China and carried out 11 projects. The cooperation majors cover many disciplines such as fine arts, music, mathematics, biological sciences, pedagogy, law, chemistry, and music. The majors of the school have conducted project cooperation with two different universities in China.

\section{Countermeasures and Suggestions}

Quality and Quantity Going Hand-in-hand to Widen the Spaces. The proposal of the Belt and Road Initiative has provided an excellent opportunity for Chinese universities to carry out international cooperation and exchanges in education and to introduce foreign high-quality educational resources. There is much room for development in the cooperation between our universities and the countries and regions along the route. At the same time, according to the 2016 QS World University Comprehensive Ranking, there are nearly 200 colleges and universities along the line, accounting for about one-fifth of the total number of universities in the world. In addition, there are 8 of the top 200 universities in the world along the line, and there are more than 40 colleges along the 400 top universities. Many world-class educational resources are gathered along the route. Quality also refers not only to top universities and disciplines, but also to specialty specialties and courses.

Classification Guidance and Innovative Mechanism. Due to the differences in geographical environment, historical culture, ethnic groups and religions, countries in the region are rich in culture and languages, coupled with language barriers; many domestic universities lack awareness and understanding of the current state of education in countries and regions along the route. In order to promptly and effectively introduce high-quality education resources along the route and avoid the blindness of the choice of partners in domestic universities, the education authorities should set up a platform for information sharing between Chinese and foreign educational resources, timely publicize the current state of education in the country along the line and the university's rankings, specialties, and willingness to run schools. For the domestic high-level universities such as the "985 Project" and "211 Project", more encouragement should be given to cooperation with leading universities along the line, and at the same time pay attention to the development of high-level educational projects (institutions) such as master's and doctoral programs.

Strengthen Monitoring and Optimizing the Layout of Disciplines. In view of the unbalanced distribution of academic disciplines and the convergence of professional settings of the participating schools, our education authorities should play an important role in administrative examination and approval and macro-control. For the phenomenon of "chain store" school running, in the process of approval of newly established projects (institutions), foreign parties should review the status of projects (institutions) that have already been carried out in the country, and demonstrate the feasibility of setting up new projects (institutions) from the perspective of resource bearing capacity. In the process of supervision, it is necessary to appropriately limit the activities of the "chain stores" start-up institutions in running schools in China, effectively curb the infiltration of foreign resources for poor quality education, and safeguard the interests of our schools.

Learn from and Promoting Mutual Communication. The National Outline for the Medium and Long-term Education Reform and Development Plan (2010-2020) clearly states that it is necessary to promote the overseas education of high-level educational institutions in China, strengthen international exchanges in education, and conduct extensive international cooperation and education services. Education exchange is a two-way exchange. Chinese-foreign cooperative education should be a two-way interactive process. At present, there are more than 2,000 projects (institutions) that have been imported in China, and only a hundred or more projects (institutions) have gone out. As China's economic and educational strengths have increased, China has played an increasingly important role in international exchanges, and it has gradually become a big country with global influence, and has gradually moved toward the center of the world stage. The international community has become more aware of the needs of our country. 


\section{Conclusions}

With the gradual implementation of the deployment of the Belt and Road initiative, Chinese-foreign cooperative education will usher in an outbreak. In the future, Chinese-foreign cooperation in running schools will open up a new era. China and countries along The Belt and Road Initiative will engage in more in-depth interactions and exchanges. The cooperation partners will gradually shift their tendency to cooperating with developed countries in Europe and the United States to gradually focusing on countries along The Belt and Road initiative. The European and American countries pay equal attention to the way; the school-running mode is also gradually changed from the introduction of quality education resources to the interaction between import and export; the specialties involved in higher education are also expanding along the lines of construction.

\section{Acknowledgements}

This work was supported by the Pilot joint program of comprehensive professional reform of International Economics and Trade (Joint Program, USU and NWUN) (Grant No:2017XJZYZHGGSD-01) and by the Modernization and Social Harmonious Development in Ethnic Regions: Research and Innovation Team of Northwest Minzu University (Grant No: 31920180101)

\section{References}

[1] Jiao Guozheng, Review and Reflection on Chinese-foreign Cooperative Education in Colleges and Universities, Chinese Higher Education, 10 (2001) 42-48.

[2]Lin Jinhui, Research on the introduction of quality education resources in Chinese-foreign cooperative education, Educational Research, 10 (2012)34-41.

[3] Wang Wei, Analysis of Industrial Economics in Chinese-foreign Cooperative Education in Higher Education, Higher Education Exploration, 1 (2015)26-29.

[4] Shen Qin, Business English Curriculum Based on Demand Analysis Theory in the Background of Chinese-Foreign Cooperation in Education, Asia Pacific Education, 3 (2016)81-88.

[5] Jiang Jun, Research on Chinese-Foreign Cooperative Education in Colleges and Universities to Innovate International Business Talents Training Model, Chinese Adult Education, 1 (2015)30-38.

[6] $\mathrm{Xu}$ Jiaqing, Reflections on Research-oriented Teaching of International Business of Chinese-Foreign Cooperative programs, Journal of Yangzhou University, 2(2012)60-69.

[7] Quan Yiwen, Teaching Orientation and Curriculum System Innovation of International Business Accounting under the Chinese-Foreign Cooperation Schooling Model, Chinese Market, 1(2013)75-81. 